available. The ongoing COVID-19 pandemic has surfaced the declining trust in both the public and private healthcare systems in India. It warrants the need to understand why public trust in healthcare institutions is deteriorating. Healthcare system in India has changed over the years. It has brought in, the concepts of commercialization and new managerialism. This has changed the relationships of providers and health managers which creates an impact on public trust in the healthcare system. Indian public healthcare system is highly under-resourced and yet is the only resort for a major section of the society, especially the poor. It is widely known to be inefficient in catering to the needs of the public. The private healthcare system on the other hand has grown exponentially and has proved to be highly overprized.

Aim To draw a conceptualization of public trust in healthcare systems in the Indian context. I will be referring to the model of Public Trust in Healthcare given by Felix Gille (2017). In this model, the public sphere, where public trust is shaped by the discourse of shared experiences and perceptions about the healthcare systems, has been centralized.

Methods Qualitative Systemic Review

Current stage of work: Conceptual framework of the research has been completed and review of the articles is under progress.

Expected results Public sphere is cardinal in shaping public trust in healthcare systems. The process of consensus-building in the public sphere is constantly changing, making it dynamic. The communication channels- active, passive and feedback, shaping the public sphere are temporal. The internal changes in the healthcare systems also determine some aspects of trust.

\section{WHO AND WHAT TO TRUST IN A CRISIS? A NARRATIVE EXPLORATION OF PERSONAL AND POPULATION HEALTH THREATS}

S Yardley. Marie Curie Palliative Care Research Department, University College London

\subsection{6/bmjopen-2021-QHRN.38}

Background Healthcare crises demand decision-making under duress. Time-bound judgments, based on imperfect information, must be made while managing expectations of unpredictable outcomes. Trust is vital for all involved.

Experts characteristically use experience-based narratives to draw inferences. Paradoxically, during the Covid-19 pandemic, prevailing social mistrust of 'experts' switched to an urgent demand for expertise when much was unknown or unknowable. Professionals debated what constituted trustworthy evidence while public intolerance of ambiguity grew. Case studies, including auto-ethnography, combined with narrative analysis can be used to explore novel and complex situations with unclear boundaries between phenomenon and context.

Aims

1. Explore how different forms of uncertainty (expertise, limits of medical knowledge, and discerning which is which) impact on trust and decision-making in patient-professional relationships.

2. Compare dynamics of trust and knowledge mediation during Covid-19 with other health threats.

Methods This work (completion Feb 2021) takes a social constructionist approach, applying Labov's framework for narrative analysis to an auto-ethnographic account and purposively selected stories of Covid-19, HIV/AIDS, cancer and dementia from public media sources. The author is a frontline clinician and qualitative researcher. She is critically considering her experiences and the stories as case studies exemplifying shifting meanings of trust.

Results Identified narrative structures provide insights into variable conceptualisations of trust. Elements (e.g. values, duties, expectations) and genres within individual stories illuminate how notions of safety and risk change according to perceived level and immediacy of threat, balanced against ability to identify trustworthy knowledge. Comparisons of how professionals and patients use life experience, personal networks and external evidence sources, and how different forms of uncertainty impact the building or breaking of trust, will be presented.

Conclusions In Covid-19, disruption to usual communication modes changed trust and relational care beyond that experienced in other personal or population health crises. Understanding this may improve future decision-making and communication.

\section{Oral presentations}

\section{Theme: Conceptualising truth and trust in health related contexts and settings}

\section{Day 1: Thursday $18^{\text {th }}$ March $-13.35-14.55$}

\section{DO YOU WANT TO KNOW WHAT PUBLIC TRUST IN THE HEALTHCARE SYSTEM IS ABOUT?}

${ }^{1} \mathrm{~F}$ Gille*, ${ }^{2} \mathrm{~S}$ Smith, ${ }^{2} \mathrm{~N}$ Mays. 'Swiss Federal Institute of Technology Zurich, Switzerland; ${ }^{2}$ London School of Hygiene and Tropical Medicine, UK

10.1136/bmjopen-2021-QHRN.39

Background Public trust is essential for the well-functioning of healthcare systems. Examples of healthcare activities that are heavily dependent on high levels of public trust are vaccination, organ donation, establishment of national health records or acceptance of measures against pandemics. Despite the frequent use of the term in the public sphere and societal interest to maintain high levels of public trust, we have only a limited understanding of what public trust as a concept actually is. This conceptual uncertainty of public trust in the healthcare system poses problems for health care governance and policy making.

Aim We aimed to answer: what is public trust in the healthcare system?

Methods We analysed three English NHS case studies: an analysis of online news with readership comments concerning the care.data initiative; a secondary analysis of interviews about participants' experiences and perceptions of biobanks; and an analysis of public focus groups about perceptions of the 100,000 Genomes Project. Further, we analysed existing conceptual work and trust theory.

Results This resulted in a full conceptual framework of public trust in the healthcare system. The framework constitutes of 16 conceptual, nine framing and two effect themes. Public trust builds on information equally relating to past experiences, present perceptions and future expectations. Public trust legitimises the actions of the healthcare system as well as encourages the public to participate in healthcare-related 